Eastern Illinois University

The Keep

Faculty Research \& Creative Activity

Biological Sciences

January 2000

\title{
Binding of Urate and Caffeine to Hemocyanin of the Lobster Homarus Vulgaris (E.) As Studied by Isothermal Titration Calorimetry $\dagger$
}

Michael A. Menze

Eastern Illinois University, michael.menze@louisville.edu

Nadja Hellmann

Johannes Gutenberg Universitat, Mainz

Heinz Decker

Johannes Gutenberg Universitat, Mainz

Manfred K. Grieshaber

Heinrich-Heine-Universitat Dusseldorf

Follow this and additional works at: http://thekeep.eiu.edu/bio_fac

Part of the Biology Commons

\section{Recommended Citation}

Menze, Michael A.; Hellmann, Nadja; Decker, Heinz; and Grieshaber, Manfred K., "Binding of Urate and Caffeine to Hemocyanin of the Lobster Homarus Vulgaris (E.) As Studied by Isothermal Titration Calorimetry †" (2000). Faculty Research \& Creative Activity. 33. http://thekeep.eiu.edu/bio_fac/33 


\title{
Binding of Urate and Caffeine to Hemocyanin of the Lobster Homarus vulgaris (E.) As Studied by Isothermal Titration Calorimetry ${ }^{\dagger}$
}

\author{
Michael A. Menze, ${ }^{*, \ddagger}$ Nadja Hellmann, ${ }^{\S}$ Heinz Decker, ${ }^{\S}$ and Manfred K. Grieshaber ${ }^{\ddagger}$ \\ Institut für Zoophysiologie, Heinrich-Heine Universität, Universitätsstrasse 1, 40225 Düsseldorf, Germany, \\ and Institut für Molekulare Biophysik, Johannes-Gutenberg Universität, Jakob-Welder Weg 26, 55128 Mainz, Germany
}

Received January 4, 2000; Revised Manuscript Received May 9, 2000

\begin{abstract}
Hemocyanin serves as an oxygen carrier in the hemolymph of the European lobster Homarus vulgaris. The oxygen binding behavior of the pigment is modulated by metabolic effectors such as lactate and urate. Urate and caffeine binding to 12-meric hemocyanin $(\mathrm{H}$. vulgaris) was studied using isothermal titration calorimetry (ITC). Binding isotherms were determined for fully oxygenated hemocyanin between $\mathrm{pH} 7.55$ and 8.15. No $\mathrm{pH}$ dependence of the binding parameters could be found for either effector. Since the magnitude of the Bohr effect depends on the urate concentration, the absence of any $\mathrm{pH}$ dependence of urate and caffeine binding to oxygenated hemocyanin suggests two conformations of the pigment under deoxygenated conditions. Urate binds to two identical binding sites $(n=2)$ each with a microscopic binding constant $K$ of $8500 \mathrm{M}^{-1}$ and an enthalpy change $\Delta H^{\circ}$ of $-32.3 \mathrm{kcal} \mathrm{mol}^{-1}$. Caffeine binds cooperatively to hemocyanin with two microscopic binding constants: $K_{1}=14100 \mathrm{M}^{-1}$ and $K_{2}=40400$ $\mathrm{M}^{-1}$. The corresponding enthalpy changes in binding are as follows: $\Delta H^{\circ}{ }_{1}=-23.3 \mathrm{kcal} \mathrm{mol}^{-1}$ and $\Delta H^{\circ}{ }_{2}=-27.1 \mathrm{kcal} \mathrm{mol}^{-1}$. The comparison of urate and caffeine binding to the oxygenated pigment indicates the existence of two protein conformations for oxygen-saturated hemocyanin. Since effector binding is not influenced by protons, four different conformations are required to create a convincing explanation for caffeine and urate binding curves. This was predicted earlier on the basis of the analysis of oxygen binding to lobster hemocyanin, employing the nesting model.
\end{abstract}

The hemocyanins of arthropods are large, extracellular, copper-containing proteins that serve as oxygen carriers which consist of one, two, four, six, or eight basic hexameric assemblies. Their apparent molecular masses range from 0.45 $\times 10^{6}$ to $3.9 \times 10^{6} \mathrm{Da}(1-6)$. Each monomeric subunit carries a single binuclear copper-containing active site which can reversibly bind a dioxygen molecule (7). Hemocyanins of arthropods exhibit high cooperative oxygen binding and allosteric regulation, thus maintaining efficient uptake and delivery of oxygen.

The effect of $\mathrm{pH}$ on the oxygen affinity of hemocyanins has been extensively studied, and most arthropod hemocyanins exhibit normal Bohr effects; that is, the oxygen affinity decreases when the $\mathrm{pH}$ becomes more acidic $(8-10)$. In contrast, all other modulators of arthropod hemocyanins increase the oxygen affinity. The modulators consist of a range of different chemical substances which probably bind to different areas in the hemocyanin molecule. Modulators are divalent cations such as $\mathrm{Mg}^{2+}$ and $\mathrm{Ca}^{2+}(11,12)$, the metabolites lactate (13) and urate (14-17), neuroactive

\footnotetext{
$\dagger$ This work was supported by the Deutsche Forschungsgemeinschaft (Grant 456/20-1), the State of Nordrhein-Westfalen (M.K.G.), and the Naturwissenschaftlich-Medizinisches-Forschungszentrum of the University of Mainz (H.D.).

* To whom correspondence should be addressed: Institut für Zoophysiologie, Heinrich-Heine Universität, Universitätsstrasse 1, 40225 Duesseldorf, Germany. Phone: 0049-211-811-4242. Fax: 0049211-811-3897. E-mail: mmenze@hotmail.com.

Heinrich-Heine Universität.

§ohannes-Gutenberg Universität.
}

compounds such as dopamine and related cardiac neuroamines $(18,19)$, and the excretory products ammonium and trimethylamine (20).

The oxygen binding characteristics of the 12-meric hemocyanin from the European lobster Homarus vulgaris (E.) in the presence of urate and L-lactate have been analyzed in detail by several authors $(21,22)$. The effects of both metabolites on oxygen affinity were found to be additive, and urate caused a significant decrease in the Bohr coefficient (23) which indicates a thermodynamical linkage between the two effectors, protons and urate. The urate analogue caffeine, also described as a potent effector of oxygen affinity (24), was found to have a higher binding constant for hemocyanin than urate in $H$. vulgaris (21).

These results have been indirectly obtained by analyzing the effector-induced changes in the half-saturation oxygen pressure $\left(p_{50}\right)$ of the hemocyanin or by equilibrium dialysis. Until now, no studies on the binding behavior of urate and its dependence on $\mathrm{pH}$ have been published. However, in this study, direct insights into the interacting forces between urate and caffeine in the dodecameric hemocyanin of $H$. vulgaris were gained using isothermal titration calorimetry (ITC). ${ }^{1}$ This method readily lends itself to the simultaneous determination of the binding constant $(K)$, the stoichiometry of ligand-protein interaction $(n)$, and $\Delta H^{\circ}$, the reaction en-

\footnotetext{
${ }^{1}$ Abbreviations: ITC, isothermal titration calorimetry; [Hc], concentration of dodecameric hemocyanin; HEPES, $N$-(2-hydroxyethyl)piperazine- $N^{\prime}$-2-ethanesulfonicacid; TRIS, tris(hydroxymethyl)aminoethane; TRICINE, $N$-tris(hydroxymethyl)methylglycine.
} 
thalpy (25). Two major questions can be addressed by this study. Is there any thermodynamical linkage between the effectors urate and caffeine and protons on the level of the conformations dominating under oxygenated conditions? Are there any ionizable groups with a $\mathrm{p} K_{\mathrm{a}}$ between $\mathrm{pH} 7.55$ and 8.15 involved in the binding of urate or caffeine? To evaluate these two questions, caffeine and urate binding to the hemocyanin (H. vulgaris) was studied at different $\mathrm{pH}$ values and in buffers having different enthalpies of proton ionization.

\section{METHODS}

Purification of Hemocyanin. Male European lobsters $[H$. vulgaris (E.)] were obtained from a marine animal wholesaler (Hummer Petersen, Hamburg, Germany). The lobsters were maintained in 33\% circulating seawater and at a temperature of $15 \pm 1{ }^{\circ} \mathrm{C}$. Hemolymph was drawn from the segment joint of the penultimate pereiopods into an ice-chilled syringe, and samples from three to five lobsters were pooled. The hemolymph samples were immediately centrifuged at $27000 \mathrm{~g}$ for $1.5 \mathrm{~h}$ at $4{ }^{\circ} \mathrm{C}$ to remove cellular debris. The supernatant was dialyzed against TRIS buffer ( $20 \mathrm{mM}$ TRIS-HCl buffer containing $40 \mathrm{mM} \mathrm{NaCl}, 20 \mathrm{mM} \mathrm{MgCl}$, and $20 \mathrm{mM} \mathrm{CaCl}_{2}$ adjusted to $\mathrm{pH} 8.0$ at $20^{\circ} \mathrm{C}$ ) using a dialysis membrane with a $20 \mathrm{kDa}$ molecular mass cutoff. To remove denatured proteins, the dialyzed sample was centrifuged again at $27000 \mathrm{~g}$ for $1.5 \mathrm{~h}$ at $4{ }^{\circ} \mathrm{C}$. The $24 \mathrm{~S}$ hemocyanin was then sedimented by ultracentrifugation for $3.5 \mathrm{~h}$ at $170000 \mathrm{~g}$ and $4{ }^{\circ} \mathrm{C}$. After centrifugation, the light reddish supernatant was discarded, leaving the hemocyanin in a dark blue pellet. It was resuspended in a sufficient amount of TRIS buffer and again centrifuged at $27000 \mathrm{~g}$ for $1.5 \mathrm{~h}$ at $4{ }^{\circ} \mathrm{C}$. Protein concentrations were determined by measuring the optical absorbance at $280 \mathrm{~nm}$ using an extinction coefficient of 1.42 $\mathrm{cm}^{2} \mathrm{mg}^{-1}$. Hemocyanin concentrations were determined by measuring the optical absorbance at $334 \mathrm{~nm}$ using an extinction coefficient of $0.269 \mathrm{~cm}^{2} \mathrm{mg}^{-1}$ for oxygen-saturated 12 -meric hemocyanin and a molecular mass of $900000 \mathrm{Da}$ (26). About $80 \mathrm{mg}$ of protein, in a volume of $2 \mathrm{~mL}$ of TRIS buffer, was loaded on a Resource $\mathrm{Q}$ anion-exchange column (Amersham Pharmacia Biotech, Freiburg, Germany) with a bed volume of $6 \mathrm{~mL}$. The column was washed with $24 \mathrm{~mL}$ of TRIS buffer and developed at a flow rate of $6 \mathrm{~mL} \mathrm{~min}^{-1}$ using $120 \mathrm{~mL}$ of a linear gradient of $500 \mathrm{mM} \mathrm{NaCl}$ dissolved in TRIS buffer. The hemocyanin eluted at a $\mathrm{NaCl}$ concentration of about $350 \mathrm{mM}$. Appropriate fractions were pooled and concentrated by ultracentrifugation $(5 \mathrm{~h}$ at $170000 \mathrm{~g}$ and $4{ }^{\circ} \mathrm{C}$ ). The pellet was again resuspended in a sufficient amount of buffer. This hemocyanin solution contained an average protein concentration of $80 \mu \mathrm{M}$ and was homogeneous as judged from native gel electrophoresis.

Controlling the Aggregation State. The aggregation state of the hemocyanin, as well as the purity of the hemocyanin solution, was controlled by a Superose 6b (Amersham Pharmacia Biotech) size exclusion column with a $24 \mathrm{~mL}$ bed volume and equilibrated with TRIS buffer containing 500 $\mathrm{mM} \mathrm{NaCl}$. About $80 \mu \mathrm{g}$ of the protein in a volume of 100 $\mu \mathrm{L}$ was applied and eluted at a flow rate of $0.2 \mathrm{~mL} \min ^{-1}$ with the same buffer. The aggregation state of the hemocyanin, which had an absorbance ratio $A_{280} / A_{334}$ of $4.8-5.0$, was found to consist of $95 \%$ dodecameric and $5 \%$ higheraggregate forms. A possible influence of the different $\mathrm{pH}$ and buffer components used in the ITC experiments on the aggregation state of the hemocyanin was also checked using the same procedure except that the same buffers were used as in the calorimetry experiments. No influence of the $\mathrm{pH}$ and buffer compositions on the aggregation state of the hemocyanin was found.

Isothermal Titration Calorimetry (ITC). All calorimetric experiments were performed with a VP-ITC titration calorimeter (MicroCal Inc., Northampton, MA). Protein solutions were prepared by dialysis of a hemocyanin stock solution against $100 \mathrm{mM}$ HEPES, TRIS, and TRICINE buffer at 4 ${ }^{\circ} \mathrm{C}$ adjusted to the $\mathrm{pH}$ values desired for the experiments. Each buffer contained $20 \mathrm{mM} \mathrm{CaCl}_{2}, 20 \mathrm{mM} \mathrm{MgCl} 2$, and $150 \mathrm{mM} \mathrm{NaCl}$. Ligand solutions were prepared by dissolving weighed amounts of urate or caffeine in the respective buffer. Urate concentrations were checked spectrophotometrically using an extinction coefficient $E_{293}$ of $12.6 \mathrm{~cm}^{2} \mu \mathrm{mol}^{-1}$ (27). Heats of reaction were determined during repeated injections of a fixed amount of ligand into a solution of hemocyanin. The injection syringe was rotated at $310 \mathrm{rpm}$ for the duration of each experiment, and the time interval between injections was about $400 \mathrm{~s}$. The heat change accompanying the addition of buffer to hemocyanin and the heat of dilution of the ligands were subtracted from the raw data after correction for the injection signal of buffer into buffer. Titration curves were analyzed using Origin software (MicroCal Inc.). A multiple-noninteracting site model and a multisite interactive model were used to analyze the data. The integral form of the phenomenological equation for the single-site case, expressed in terms of the molar concentration of the unbound ligand $[\mathrm{L}]$, is given by eq 1 :

$$
q=\frac{\left(n\left[\mathrm{M}_{\mathrm{T}}\right] V\right) \Delta H^{\circ} K[\mathrm{~L}]}{1+K[\mathrm{~L}]}
$$

where $q$ is the heat developed on adding $\mathrm{L}$ to a macromolecule. The total macromolecule concentration in the binding process is $\left[\mathrm{M}_{\mathrm{T}}\right]$ with $n$ binding sites. The binding process is characterized by a binding constant $K\left(\mathrm{M}^{-1}\right)$ and an enthalpy of $\Delta H^{\circ}$ in a total volume $V$. The integral form of the equation for the multisite interactive model is given by eq 2 :

$$
\begin{gathered}
\frac{q}{\left[\mathrm{M}_{\mathrm{T}}\right] V}=\left[\left(\Delta H^{\circ}{ }_{1}\right) K_{1}[\mathrm{~L}]+\left(\Delta \mathrm{H}^{\circ}{ }_{1}+\Delta H^{\circ}{ }_{2}\right) K_{1} K_{2}[\mathrm{~L}]^{2}+\right. \\
\left.\left(\Delta H^{\circ}{ }_{1}+\Delta H^{\circ}{ }_{2}+\ldots \Delta H^{\circ}\right) K_{1} K_{2} \ldots K_{i}[\mathrm{~L}]^{i}\right] / \\
\left(1+K_{1}[\mathrm{~L}]+K_{1} K_{2}[\mathrm{~L}]^{2}+K_{1} K_{2} \ldots K_{i}[\mathrm{~L}]^{i}\right)
\end{gathered}
$$

where $\Delta H^{\circ}$ is the molar enthalpy of ligand binding to the $i$ th site and $K_{i}$ is the corresponding binding constant $\left(\mathrm{M}^{-1}\right)$ for each individual binding site. In the most general case, no analytic form for $q$ that is dependent on the total ligand concentration $\left[\mathrm{L}_{\mathrm{T}}\right]$ can be found. Therefore, the problem is usually solved numerically during the fitting routine, using computer programs such as Origin. On the basis of the numerical solution, the differential form of the binding function is obtained. In the work presented here, the Microcal Origin program (MicroCal Inc.) was used. A detailed discussion of this equations is presented by Indyk and Fisher (28).

\section{RESULTS}

Binding of Urate and Caffeine to Hemocyanin. The heat dissipation during isothermal titration of 12-meric hemocya- 


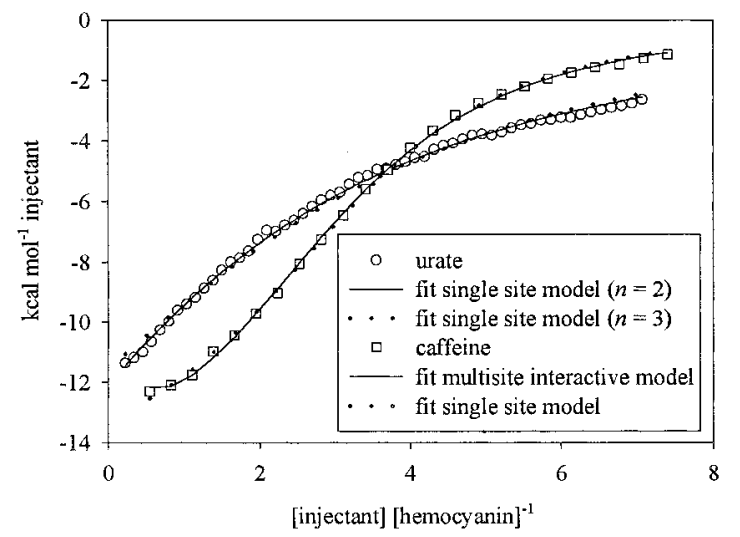

FIGURE 1: Titration of urate and caffeine into hemocyanin of $H$. vulgaris. The caffeine titration (squares) was performed by injecting $24 \times 10 \mu \mathrm{L}$ of $1 \mathrm{mM}$ caffeine into $26 \mu \mathrm{M}$ hemocyanin, and the urate binding isotherm (circles) was determined by making $54 \times 5$ $\mu \mathrm{L}$ injections of $1 \mathrm{mM}$ urate into $33.3 \mu \mathrm{M}$ hemocyanin. Both titrations were carried out in HEPES buffer at $\mathrm{pH} 8.0$ and $20^{\circ} \mathrm{C}$. The influences of different models and stoichiometry on the quality of the obtained fits are visualized graphically (lines). See the text for further references.

nin of $H$. vulgaris with urate and caffeine is shown in Figure 1. Each point represents the heat $\Delta q$ per mole of injectant liberated for an incremental addition of the injectants urate and caffeine, versus the ratio of the accumulated total injectant concentration $\left[\mathrm{L}_{\mathrm{T}}\right]$ divided by the concentration of hemocyanin $\left[\mathrm{M}_{\mathrm{T}}\right]$. This form of a plot is essentially the first derivative $\left(\Delta q \Delta\left[\mathrm{L}_{\mathrm{T}}\right]^{-1}\right)$ of a convential binding curve in which the total accumulated signal is plotted versus the total accumulated injectant concentration. The graph depicts the typical enthalpic binding isotherms of caffeine and urate at $\mathrm{pH} 8.0$, which is the in vivo $\mathrm{pH}$ of the hemolymph under normoxic conditions (C. R. Bridges, personal communication). The evaluation of the binding constant $(K)$, the number of binding sites $(n)$, and the enthalpy change $\left(\Delta H^{\circ}\right)$ for urate was difficult because the product of $K, n$, and the protein concentration $\left[\mathrm{M}_{\mathrm{T}}\right]$ was low. Under these conditions, $n$ is highly correlated with $\Delta H^{\circ}$ in the fitting process. This problem could in principle be solved if the protein concentration $\left[\mathrm{M}_{\mathrm{T}}\right]$ could be raised to such an extent that a high value of the product of $K, n$, and $\left[\mathrm{M}_{\mathrm{T}}\right]$ would result (29, 30 ). Unfortunately, this is impossible because hemocyanin precipitates at the required concentrations. Furthermore, the solubility of urate in the buffers that are used is limited to about $1 \mathrm{mM}$. If $n$ is not fixed to a certain value such as 2 or 3 , the fitting process fails to converge. Therefore, the number of binding sites for urate was fixed in the fitting routine on the basis of a value determined in equilibrium dialysis experiments (21) where two binding sites for urate in the 12-meric hemocyanin were found. If the number of urate binding sites was fixed to 2 for a multiple-noninteracting site model, a binding constant $K$ of $7500 \pm 1500 \mathrm{M}^{-1}$ and an enthalpy change $\Delta H^{\circ}$ of $-34.7 \pm 0.4 \mathrm{kcal} \mathrm{mol}^{-1}$ were found for data obtained at $\mathrm{pH} 8.0$ (Figure 1).

The characteristics of binding of caffeine to hemocyanin can be analyzed without preset values for the number of binding sites $(n)$ when a multiple-noninteracting binding site model is used. The best fit of the caffeine binding curve (Figure 1) resulted in a value for $n$ of $3.2 \pm 0.04$, a binding constant $K$ of $71100 \pm 4200 \mathrm{M}^{-1}$, and an enthalpy change $\Delta H^{\circ}$ of $-14.9 \pm 0.4 \mathrm{kcal} \mathrm{mol}^{-1}$. Assuming a value of 2 or any other number of binding sites resulted in a significant reduction in the level of agreement between the data and the fitted curve.

Because the analysis of caffeine binding to hemocyanin indicated the presence of three binding sites, we also analyzed urate binding to the pigment assuming three binding sites for this metabolite. The fitted curve, however, shows a higher deviation from the measured data than when 2 binding sites are assumed (Figure 1). Since the difference between both fits can hardly be seen ad oculus in Figure 1, the degree of similarity between the fitted curve and the data measured was based on the $\chi^{2}$ value. This value increases from 20100 to 66400 if the number of binding sites of urate binding is fixed at 3, indicating that 3 binding sites for urate in the dodecameric hemocyanin are less probable than 2 .

When the similar structures of the two effectors and the fact that caffeine is able to inhibit urate binding completely (21) are considered, a different stoichiometry of binding of the two purines is unlikely. If we allowed for the occurrence of cooperativity by analyzing caffeine binding with a multisite interactive model, the isothermic titration of caffeine to the 12-meric hemocyanin can be analyzed assuming $n=$ 2 (Figure 1). In this case, the $\chi^{2}$ value drops from 30300 to 11400 , indicating a better fit. The microscopic binding constants for caffeine and urate binding to hemocyanin are summarized in Tables 1 and 2 .

Influence of $\mathrm{pH}$ on the Binding of Caffeine and Urate. From Figure 2, it is obvious that the binding isotherms measured at similar hemocyanin concentrations coincide. The average values of the two microscopic binding constants for caffeine binding to hemocyanin were determined to be $14100 \pm 5800 \mathrm{M}^{-1}\left(K_{1}\right)$ and $40400 \pm 4500 \mathrm{M}^{-1}\left(K_{2}\right)$ with similar enthalpy changes of binding: $\Delta H^{\circ}{ }_{1}=-23.3 \pm 3.7$ kcal mol ${ }^{-1}$ and $\Delta H^{\circ}{ }_{2}=-27.1 \pm 1.2 \mathrm{kcal} \mathrm{mol}^{-1}$. Urate binding to both sites can $(n=2)$ be described with a binding constant $K$ of $8500 \pm 1600 \mathrm{M}^{-1}$ and an enthalpy change $\Delta H^{\circ}$ of $-32.3 \pm 2.3 \mathrm{kcal} \mathrm{mol}^{-1}$. The variations in the binding constants at any given $\mathrm{pH}$ are within the error of the analysis and cannot be attributed to the differences in the proton concentrations. Thus, protons do not influence caffeine and urate binding in the $\mathrm{pH}$ range of 7.55-8.15.

Dependence of $\Delta H^{\circ}$ on the Buffer System. The lack of any $\mathrm{pH}$ dependence between $\mathrm{pH} 7.55$ and 8.15 of caffeine binding to hemocyanin indicates that no amino groups with $\mathrm{p} K_{\mathrm{a}} \mathrm{s}$ in this region are involved in the binding process, either directly at the binding sites or at any site where conformational changes as a result of effector binding occur. It seems, therefore, that no proton transfer is involved at all. To verify this result, caffeine binding was studied at $\mathrm{pH} 8.0$ in three different buffer systems (TRIS, HEPES, and TRICINE) characterized by differing heats of proton dissociation (4.9$\left.11.51 \mathrm{kcal} \mathrm{mol}^{-1}\right)$. A change in the $\mathrm{p} K_{\mathrm{a}}$ of any of the amino groups involved in effector binding should result in proton transfer between the binding complex and the buffer molecules. In this case, the apparent enthalpy of binding $\left(\Delta H^{\circ}\right.$ app $)$ includes both the intrinsic enthalpy of effector binding $\left(\Delta H^{\circ}\right.$ int $)$ and the enthalpy of ionization of the buffer system $\left(\Delta H^{\circ}{ }_{\text {ionz }}\right)$ :

$$
\Delta H_{\text {app }}^{\circ}=\Delta H^{\circ}{ }_{\text {int }}+n_{\mathrm{H}} \Delta H^{\circ}{ }_{\text {ionz }}
$$

where $n_{\mathrm{H}}$ represents the number of protons released or 
Table 1: Thermodynamic Parameters for the Binding of Caffeine and Urate to Hemocyanin of $H$. vulgaris in HEPES Buffer ${ }^{a}$

\begin{tabular}{|c|c|c|c|c|c|c|}
\hline \multirow[b]{2}{*}{$\mathrm{pH}$} & \multicolumn{4}{|c|}{ caffeine } & \multicolumn{2}{|c|}{ urate } \\
\hline & $\begin{array}{c}K_{1} \\
\left(\mathrm{mM}^{-1}\right)\end{array}$ & $\begin{array}{c}K_{2} \\
\left(\mathrm{mM}^{-1}\right)\end{array}$ & $\begin{array}{c}\Delta H^{\circ}{ }_{1} \\
\left(\mathrm{kcal} \mathrm{mol}^{-1}\right)\end{array}$ & $\begin{array}{c}\Delta H^{\circ}{ }_{2} \\
\left(\mathrm{kcal} \mathrm{mol}^{-1}\right)\end{array}$ & $\begin{array}{c}K \\
\left(\mathrm{mM}^{-1}\right)\end{array}$ & $\begin{array}{c}\Delta H^{\circ} \\
\left(\mathrm{kcal} \mathrm{mol}^{-1}\right)\end{array}$ \\
\hline 7.55 & $9.5 \pm 5.1$ & $45.6 \pm 3.6$ & $-26.2 \pm 4.9$ & $-26.1 \pm 5.9$ & $9.0 \pm 1.9$ & $-32.5 \pm 1.5$ \\
\hline 7.85 & $20.6 \pm 5.0$ & $38.1 \pm 1.7$ & $-19.1 \pm 2.5$ & $-26.9 \pm 3.3$ & $9.8 \pm 1.4$ & $-29.6 \pm 1.9$ \\
\hline 8.00 & nd & nd & & & $6.5 \pm 0.7$ & $-35.4 \pm 1.0$ \\
\hline 8.15 & $12.2 \pm 1.0$ & $37.6 \pm 3.5$ & $-24.7 \pm 2.8$ & $-28.4 \pm 3.0$ & $8.8 \pm 1.1$ & $-32.0 \pm 1.0$ \\
\hline means & $14.1 \pm 5.8$ & $40.4 \pm 4.5$ & $-23.3 \pm 3.7$ & $-27.1 \pm 1.2$ & $8.5 \pm 1.6$ & $-32.3 \pm 2.3$ \\
\hline
\end{tabular}

${ }^{a}$ Values are averages from two to five replicates of the experiment. The protein concentrations were $16.5-55.8 \mu \mathrm{M}$ (12-mers) in the urate experiments and 39.5-49.5 $\mu \mathrm{M}$ (hemocyanin) in the caffeine experiments. The ligand concentration in the syringe was $0.6,1,1.5$, or $2.0 \mathrm{mM}$. Experiments were performed at $20^{\circ} \mathrm{C}$. The errors given are standard deviations of the mean. The errors given by the fitting routine for the individual parameters are in the same range.

Table 2: Thermodynamic Data Obtained from the Titration of Caffeine into 12-meric Hemocyanin (H. vulgaris) at pH 8.0 in HEPES, TRICINE, and TRIS Buffers ${ }^{a}$

\begin{tabular}{lccccc}
\hline buffer & $\begin{array}{c}\Delta H^{\circ}{ }_{\text {ionz }} \\
\left(\mathrm{kcal} \mathrm{mol}^{-1}\right)\end{array}$ & $\begin{array}{c}K_{1} \\
\left(\mathrm{mM}^{-1}\right)\end{array}$ & $\begin{array}{c}K_{2} \\
\left(\mathrm{mM}^{-1}\right)\end{array}$ & $\begin{array}{c}\Delta H^{\circ}{ }_{1} \\
\left(\mathrm{kcal} \mathrm{mol}^{-1}\right)\end{array}$ & $\begin{array}{c}\Delta H^{\circ}{ }_{2} \\
\left(\mathrm{kcal} \mathrm{mol}^{-1}\right)\end{array}$ \\
\hline HEPES & 4.90 & $13.4 \pm 1.9$ & $73.6 \pm 4.8$ & $-27.9 \pm 2.3$ & $-20.2 \pm 2.7$ \\
HEPES & 4.90 & $12.8 \pm 1.9$ & $69.7 \pm 4.6$ & $-28.7 \pm 2.5$ & $-20.4 \pm 3.1$ \\
TRICINE & 7.76 & $13.7 \pm 2.3$ & $80.4 \pm 6.3$ & $-28.5 \pm 2.8$ & $-20.2 \pm 3.3$ \\
TRICINE & 7.76 & $12.5 \pm 2.2$ & $76.4 \pm 6.1$ & $-31.2 \pm 3.2$ & $-17.3 \pm 3.8$ \\
TRIS & 11.51 & $18.1 \pm 3.9$ & $55.7 \pm 4.6$ & $-25.8 \pm 2.3$ & $-26.1 \pm 3.0$ \\
TRIS & 11.51 & $16.4 \pm 2.8$ & $55.3 \pm 3.9$ & $-24.2 \pm 2.6$ & $-27.4 \pm 3.4$ \\
mean & & $14.5 \pm 2.2$ & $68.5 \pm 10.7$ & $-27.7 \pm 2.4$ & $-21.9 \pm 3.9$ \\
\hline
\end{tabular}

${ }^{a}$ The protein concentrations were $25.7-26.6 \mu \mathrm{M}$ (12-mers). The concentration of the injectant (caffeine) was $1.0 \mathrm{mM}$. Experiments were performed at $20{ }^{\circ} \mathrm{C}$. Each set of values are results of a single experiment. The errors given are those calculated on the basis of the least-squares analysis.

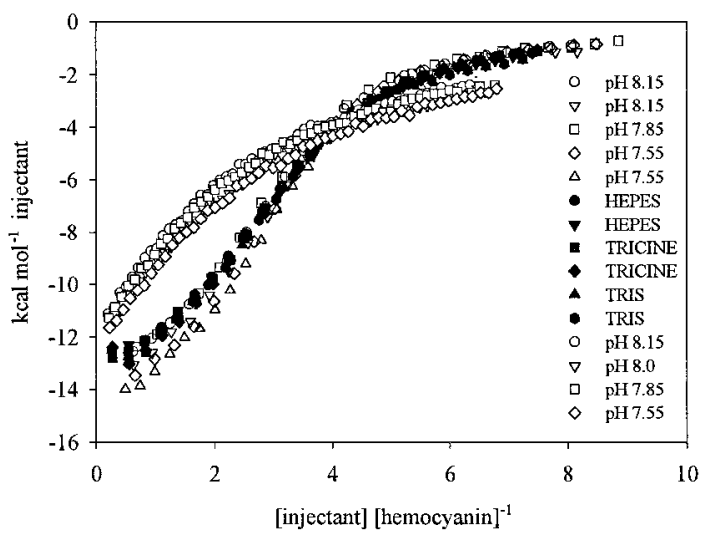

Figure 2: Binding of caffeine and urate to hemocyanin $(H$. vulgaris) at different $\mathrm{pH}$ values and in three buffer systems. The titrations were performed by injecting $24 \times 10 \mu \mathrm{L}$ of caffeine $(2$ or $1.5 \mathrm{mM}$ ) into $39.5-49.5 \mu \mathrm{M}$ hemocyanin at three different $\mathrm{pH}$ values (white symbols). The urate binding isotherms were determined by injecting $55 \times 5 \mu \mathrm{L}$ of $1 \mathrm{mM}$ urate (light gray symbols) into $31.5-36.8 \mu \mathrm{M}$ hemocyanin. The dark gray symbols represent measurements in three different buffer systems at $\mathrm{pH} 8.0$ after injection of $25 \times 10 \mu \mathrm{L}$ of $1 \mathrm{mM}$ caffeine into $25.7-26.6 \mu \mathrm{M}$ hemocyanin.

absorbed by the buffer system $(31,32)$. We found no dependence of $\Delta H^{\circ}$ app on the ionization enthalpy of the buffer (Table 2). However, a weak dependence on protein concentration in the binding parameters was found. The values for the second binding constant $\left(K_{2}\right)$ were somewhat higher at lower protein concentrations $\left[K_{2}=68.5 \pm 10.7 \mathrm{mM}^{-1}\right.$ (Table 2) when $[\mathrm{Hc}]=25.7-26.6 \mu \mathrm{M}]$ than those found at a higher protein concentration $\left[K_{2}=40.4 \pm 4.5 \mathrm{mM}^{-1}\right.$ (Table 1) when $[\mathrm{Hc}]>39.5 \mu \mathrm{M}]$.

\section{DISCUSSION}

Urate increases the oxygen affinity of hemocyanin in various crustacea $(14,24)$. In the case of $H$. vulgaris (E.), the half-saturation oxygen pressure $\left(p_{50}\right)$ of the $(2 \times 6)$-meric hemocyanin is lowered and the cooperativity is decreased. The chemical analogue caffeine affects cooperativity and affinity even more strongly than urate (33). To understand the mechanisms of allosteric interaction, effector binding has to be characterized in terms of the binding constant and stoichiometry. Calorimetric analysis of the binding process can give further insight into allosteric regulated systems. This was shown by Fisher and Tally (34), who employed the concept of isoergonic cooperativity to substrate binding in liver glutamate dehydrogenase.

In dialysis experiments, the number of binding sites for urate was found to be 2 for the $(2 \times 6)$-meric hemocyanin of $H$. vulgaris and a binding constant $K$ of $37000 \mathrm{M}^{-1}$ was determined. If it is assumed that there are 2 binding sites for caffeine, the binding constant was found to be 110000 $\mathrm{M}^{-1}(21)$. These results have been obtained by equilibrium dialysis without further analysis of the entropic and enthalpic contributions of the binding processes. Furthermore, caffeine binding was studied only indirectly by using urate competition experiments.

To gain direct insight into the thermodynamics of the interactions between urate and caffeine in the dodecameric hemocyanin of $H$. vulgaris, we reinvestigated the binding characteristics using isothermal titration calorimetry (ITC). To gain further insight into the allosteric regulation of effector binding to hemocyanin, we investigated the influence of $\mathrm{pH}$ on the binding characteristics of the two effectors to prove a possible thermodynamical linkage between urate and protons and caffeine and protons in the oxygenated hemocyanin.

Analysis of Urate and Caffeine Binding to Hemocyanin of $H$. vulgaris. The binding of urate and caffeine to the crustacean hemocyanin was studied at $20{ }^{\circ} \mathrm{C}$ within the physiological $\mathrm{pH}$ range of $7.55-8.15(35,36)$. Because the 
product of $K, n$, and $\left[\mathrm{M}_{\mathrm{T}}\right]$ for urate binding was low, the titration curves were analyzed on the basis of a preset number of binding sites $(n=2)$ according to previous equilibrium dialysis experiments (21). The binding constant, as measured by ITC, was found to be lower than the constant obtained in the previous study $\left(K=8500 \mathrm{M}^{-1}\right.$ and $K=37000 \mathrm{M}^{-1}$, respectively). The latter was determined in a physiological saline solution, using equilibrium dialysis at $15^{\circ} \mathrm{C}$, and this could explain why a higher value for the binding constant was found. However, an influence on the number of urate and caffeine binding sites in the 12-meric hemocyanin, by temperature or buffer composition, seems unlikely, which tends to justify the use of preset values in the analysis.

Unexpectedly, caffeine binding seems to involve 3.2 binding sites $(n)$ with a binding constant $K$ of $71100 \mathrm{M}^{-1}$ and an enthalpy change $\Delta H^{\circ}$ of $-14.9 \mathrm{kcal} \mathrm{mol}^{-1}$ based on a model with $n$ identical binding sites. However, caffeine binding data could also be described assuming two cooperative binding sites. The microscopic binding constants $K_{1}$ (14 $100 \mathrm{M}^{-1}$ ) and $K_{2}\left(40400 \mathrm{M}^{-1}\right)$ (by using $39.5-49.5 \mu \mathrm{M}$ hemocyanin, Table 1) indicate positive cooperativity.

Our results indicate that caffeine displays cooperative binding but urate does not. How can this be rationalized? If two protein conformations (A and B) exist for oxygenated hemocyanin, one could be present in a higher concentration $([\mathrm{A}] \gg[\mathrm{B}])$. The dominating conformation A should be characterized by a higher affinity for urate compared to that of conformation B, while caffeine binds preferably to B. With these assumptions, there would be only a slight change in the distribution between the two conformations with increasing urate concentrations. Thus, cooperativity in urate binding would not be detectable. In contrast, if caffeine were added, the conformational distribution would change significantly toward B which could lead to the observed cooperativity in binding. The hypothesis of two hemocyanin conformations under oxygenated conditions is in accordance with an analysis of the $\mathrm{pH}$ dependence of oxygen binding employing the nesting model. In this model, two conformations for the $(2 \times 6)$-meric oxygenated hemocyanin of the closely related $H$. americanus is required (8).

This study indicates the presence of two effector binding sites for urate in the $(2 \times 6)$-meric hemocyanin $(H$. vulgaris $)$. A possible binding site for the allosteric effector would be along the 3-fold symmetry axis of each hexamer. Binding of an effector at this site could arrest the conformational transition within the allosteric unit, the hexamer.

Remarkably, the hemocyanin concentration was found to have a weak influence on the caffeine binding parameters. The $K_{1}$ parameter of caffeine binding seems to be relatively unaffected by the hemocyanin concentration. However, the $K_{2}$ value shows a slight increase at lower hemocyanin concentrations from $40100 \mathrm{M}^{-1}$ at $39.5-49.5 \mu \mathrm{M}$ hemocyanin to $68500 \mathrm{M}^{-1}$ at $25.7-26.5 \mu \mathrm{M}$ (Tables 1 and 2). Although this is a small variation, it is greater than expected, in view of the deviations in $K$ values seen within both concentration ranges. A decrease in the binding constant with increasing protein concentrations is also described for the binding of cAMP to RNAse (29). This trend might suggest the appearance of higher than dodecameric hemocyanin assemblies, with increasing protein concentrations, which differ in their binding characteristics for caffeine.
Influence of $\mathrm{pH}$ on Urate and Caffeine Binding to Hemocyanin of $H$. vulgaris. There is no $\mathrm{pH}$ dependence of urate and caffeine binding in the $\mathrm{pH}$ range between 7.55 and 8.15. This is apparent without any detailed analysis, since the binding isotherms measured at similar hemocyanin concentration coincide (Figure 2). This is supported by the result that caffeine binding is not linked to proton transfer between the buffer system and the binding complex. Otherwise, a dependence of the binding parameters on $\mathrm{pH}$ or a change of $\Delta H^{\circ}$ app with buffer composition would have been observed (Tables 1 and 2). Thus, the experimentally obtained binding enthalpy corresponds only to the enthalpy change due to binding of caffeine, and no change in the $\mathrm{p} K_{\mathrm{a}}$ of any amino acid is involved when binding occurs. Since caffeine lacks any charged side groups and has a higher affinity than urate, we propose that binding is largely driven by hydrophobic interactions.

Physiological Considerations. Under hypoxic conditions, urate concentrations in the hemolymph of some decapod Crustacea increase $(16,37)$ which is due to a decrease in uricase activity lacking the second substrate oxygen $(34,38)$. Increasing concentrations of urate shift the $p_{50} \mathrm{~s}$ of oxygen binding curves toward lower values. This might enable a sufficient oxygen loading of hemocyanin at the gills under hypoxic conditions. In this study, we found a binding constant $K$ of about $8500 \mathrm{M}^{-1}$, corresponding to a halfsaturation of hemocyanin at $120 \mu \mathrm{M}$ urate. The total urate concentration in the hemolymph of $H$. vulgaris was determined to about $80 \mu \mathrm{M}$ under normoxic conditions (23). It is important to realize that the circulating urate concentration is never truly zero and thus will have some role in determining the oxygen affinity of the pigment in quiescent, nonstressed animals. For a typical value of $35 \mu \mathrm{M}$ for the hemocyanin concentration of lobster hemolymph $(34.9 \pm$ $4.9 \mu \mathrm{M}$; data not shown), the pigment is loaded to only $33 \%$ with urate so that the affinity has probably been optimized with respect to the physiological concentration of the effector. Under extreme hypoxia, the urate concentration increases to $160 \mu \mathrm{M}$ (33). Under this condition, the hemocyanin would be saturated with urate to about $51 \%$. Since the saturation level is changed only moderately when the urate concentration is raised from 80 to $160 \mu \mathrm{M}$, one would expect only a relatively small change in the $p_{50}$ for oxygen binding. It is interesting to note, therefore, that only a slight shift in the $p_{50}$, from about 5.8 to 5.2 Torr, upon increasing the urate concentration from 120 to $170 \mu \mathrm{M}$ is reported by Zeiss et al. (23).

The shift of $p_{50}$ due to urate binding was investigated as a function of $\mathrm{pH}(23)$, and the Bohr effect was found to be reduced with increasing urate concentrations. This indicates that the allosteric interaction depends on $\mathrm{pH}$. Precisely which hemocyanin conformations were susceptible to $\mathrm{pH}$ changes, with respect to urate binding affinity, were unknown. In our study, we found that binding to fully oxygenated hemocyanin is independent of $\mathrm{pH}$. Consequently, we expect that $\mathrm{pH}$ regulates the urate binding on those conformations which are predominant in deoxygenated hemocyanin. The existence of two conformations in the deoxygenated state which differ in their affinity for protons and urate could explain such a behavior. This could also account for the change in the affinity of the first oxygen bound to hemocyanin, when the urate concentration is altered (21). 


\section{REFERENCES}

1. Bonaventura, J., and Bonaventura, C. (1980) Am. Zool. 20, $7-17$.

2. van Holde, K. E., and Miller, K. I. (1995) Adv. Protein Chem. $47,1-81$.

3. Ellerton, H. D., Ellerton, N. F., and Robinson, H. A. (1983) Prog. Biophys. Mol. Biol. 41, 143-248.

4. Linzen, B., Soeter, N. M., Riggs, A. F., Schneider, H. J., Schartau, W., Moore, M. D., Yokota, E., Behrens, P. Q., Nakashima, H., Takagi, T., Nemoto, T., Vereijken, J. M., Bak, H. J., Beintema, J. J., Volbeda, A., Gaykema, W. P. J., and Hol, W. G. J. (1985) Science 229, 519-524.

5. Herskovits, T. T. (1988) Comp. Biochem. Physiol. 91B, 597611.

6. Markl, J., and Decker, H. (1992) Adv. Comput. Environ. Physiol. 13, 325-376.

7. Salvato, B., and Beltramini, M. (1990) Chem. Rep. 8, 1-47.

8. Decker, H., and Sterner, R. (1990) J. Mol. Biol. 211, 281293.

9. Truchot, J. P. (1992) Adv. Comput. Environ. Physiol. 13, 377410.

10. van Holde, K. E., and Miller, K. I. (1982) Q. Rev. Biophys. $15,1-129$.

11. Larimer, J. L., and Austen, F. R. (1964) Comp. Biochem. Physiol. 13, 35-46.

12. Mangum, C. P. (1980) Am. Zool. 20, 19-38.

13. Truchot, J. P. (1980) Comp. Biochem. Physiol. 57B, 205208.

14. Morris, S., Bridges, C., and Grieshaber, M. K. (1985) J. Exp. Zool. 235, 135-139.

15. Bridges, C. R., and Morris, S. (1986) in Invertebrate oxygen carrier (Linzen, B., Ed.) pp 341-352, Springer-Verlag, Berlin.

16. Lallier, F., Boitel, F., and Truchot, J. P. (1987) Comp. Biochem. Physiol. 86A, 255-260.

17. Lallier, F., and Truchot, J. P. (1989) Respir. Physiol. 77, 323336.

18. Morris, S., and McMahon, B. R. (1989) J. Exp. Biol. 249, 334-337.

19. Morris, S. (1990) Physiol. Zool. 63 (2), 253-287.
20. Sanders, N. K., Morris, S., Childress, J. J., and McMahon, B. R. (1992) Comp. Biochem. Physiol. 101A, 511-516.

21. Nies, A., Zeis, B., Bridges, C. R., and Grieshaber, M. K. (1992) J. Exp. Biol. 168, 111-124.

22. Bouchet, J. Y., and Truchot, J. P. (1985) Comp. Biochem. Physiol. 80A, 69-73.

23. Zeis, B., Nies, A., Bridges, C. R., and Grieshaber, M. K. (1992) J. Exp. Biol. 168, 93-110.

24. Morris, S., Bridges, C. R., and Grieshaber, M. K. (1986) J. Comput. Physiol. 156B, 431-440.

25. Ladbury, J. E., and Chowdhry, B. Z. (1996) Chem. Biol. 3, $791-801$.

26. Nickerson, K. W., and van Holde, K. E. (1971) Comp. Biochem. Physiol. 39B, 855-872.

27. Scheibe, P., Bernt, E., and Bergmeyer, H. U. (1974) in Methoden der enzymatischen Analyse (Bergmeyer, H. U., Ed.) pp 1999-2002, Verlag Chemie, Weinheim, Germany.

28. Indyk, L., and Fisher, H. F. (1998) Methods Enzymol. 295, $350-364$.

29. Wiseman, T., Williston, S., Brandts, J. F., and Linn, L. N. (1989) Anal. Biochem. 179, 131-137.

30. Kavanoor, M., and Eftink, M. R. (1997) Biophys. Chem. 66, $43-55$.

31. Gomez, J., and Freire, E. (1995) J. Mol. Biol. 252, 337-350.

32. Baker, B. M., and Murphy, K. P. (1996) Biophys. J. 71, 20492055.

33. Zeis, B. (1994) Einfluss von Urat auf die funktionellen Eigenschaften von Hämocyanin, Inaugaral Dissertation, Verlag Shaker, Aachen, Germany.

34. Fisher, F. H., and Tally, J. (1998) Methods Enzymol. 295, 331349.

35. Terwilliger, N. B. (1998) J. Exp. Biol. 201, 1085-1098.

36. Graham, R. A., Mangum, C. P., Terwilliger, R. C., and Terwilliger, N. B. (1983) Comp. Biochem. Physiol. 74A, 4550.

37. Czytrich, H. M., Bridges, C. R., and Grieshaber, M. K. (1987) Verh. Dtsch. Zool. Ges. 80, 207.

38. Dykens, A. J. (1991) Comp. Biochem. Physiol. 98B, 579-582. BI000008L 